\title{
A Quantitative Ultrastructural Study of Microtubule Content and Secretory Granule Accumulation in Parathyroid Glands of Phosphate- and Colchicine-Treated Rats
}

\author{
Eve P. Reaven and Gerald M. Reaven \\ From the Department of Medicine, Stanford University School of Medicine and \\ Veterans Administration Hospital, Palo Alto, California 94304
}

\begin{abstract}
A в S T R A C T Microtubule involvement in secretory events of the parathyroid gland was investigated in rats treated with colchicine and/or phosphorus, agents which have been shown to modify parathyroid secretion. Quantitative ultrastructural techniques were used in an effort to assess the cytoplasmic microtubule and secretory granule content of chief cells $3 \mathrm{~h}$ after treatment, when hypocalcemia was well established. After colchicine administration, the chief cells appeared to have lost all assembled microtubules and accumulated greater than normal amounts of cytoplasmic secretory granules. On the other hand, phosphorus treatment was associated with increased microtubule content although the cytoplasmic content of secretory granules remained unchanged. When colchicine and phosphorus were given concomitantly, microtubules were again absent, but the secretory granule content of the cells was markedly increased.

These data provide direct evidence that colchicine disrupts assembled microtubules in chief cells of rat parathyroids; the consequence of this effect appears to be a blockage of hormone release which is reflected in the accumulation of secretory granules in the cell. The fact that microtubules also show a significant increase in content when hormone release from chief cells is presumed to increase, suggests that microtubules may participate in the physiological control of parathyroid hormone secretion.
\end{abstract}

\section{INTRODUCTION}

Antimitotic agents such as colchicine and vinblastine sulfate have been shown to interfere with secretion in

Dr. Gerald M. Reaven is a Medical Investigator (MRIS 7363), Veterans Administration.

Received for publication 25 September 1974 and in revised form 21 February 1975. several organs (1-17), including that of the parathyroid gland. Colchicine inhibits the conversion of proparathyroid hormone to parathyroid hormone in incubated slices of bovine parathyroid gland (5), and vinblastine sulfate inhibits the release of parathyroid hormone from incubated parathyroid glands $(4,14)$. Although the precise mechanism by which these antimitotic agents affect secretion has not been clarified, it has been postulated that the effect is secondary to the ability of colchicine and vinblastine to prevent normal assembly of microtubules by binding to microtubule subunit protein (18-20). Although there is good evidence that colchicine and vinblastine bind to isolated microtubule protein, and good evidence to suggest that colchicine and vinblastine interfere with the translocation of secretory products in intact cells, there is little direct evidence to show that the assembled microtubules, which appear to be randomly distributed in the cytoplasm of all secretory cells, participate in this process.

To provide such evidence, the present study was carried out in which the cytoplasmic microtubule and secretory granule content of parathyroid gland chief cells was quantitated in rats in which parathyroid hormone secretion was modified by the administration of colchicine (5) or phosphorus (21).

\section{METHODS}

Experimental protocol. Female Sprague-Dawley rats weighing approximately $200 \mathrm{~g}$ were injected with either intravenous saline, intraperitoneal $0.15 \mathrm{M}$ sodium phosphate (150 mg phosphorus $/ \mathrm{kg}$ body $\mathrm{wt}$ ), intravenous colchicine $(0.25-5.0 \mathrm{mg} / \mathrm{kg}$ body $\mathrm{wt})$, or a combination of sodium phosphate (150 mg phosphorus/kg body wt) and colchicine ( $2.5 \mathrm{mg} / \mathrm{kg}$ body $\mathrm{wt}$ ). Blood was drawn for plasma calcium determination (22) 90 and $180 \mathrm{~min}$ after treatment.

Tissue preparation. Parathyroid glands were removed $180 \mathrm{~min}$ after treatment and fixed overnight in either $1.5 \%$ glutaraldehyde prepared in $0.1 \mathrm{M}$ cacodylate buffer ( $\mathrm{pH}$ 7.2,

The Journal of Clinical Investigation Volume 56 July 1975.49-55 


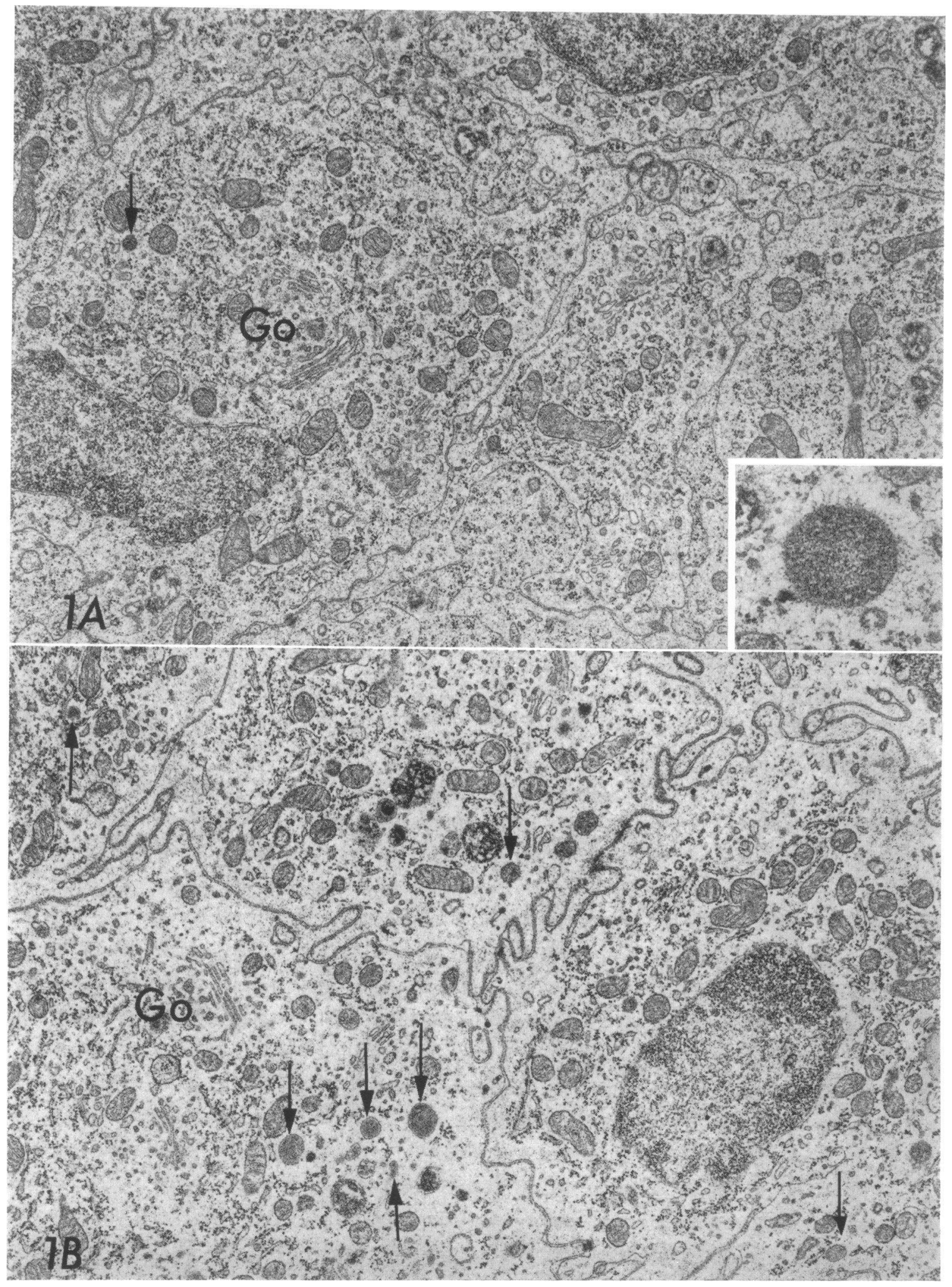

FIGURE 1 Low power view of portions of several chief cells from parathyroid glands in which osmium tetroxide was used as a primary fixative to preserve cytoplasmic inclusion 
$22^{\circ} \mathrm{C}, 375$ mosmol), or in $1 \%$ osmium tetroxide in Millonig's

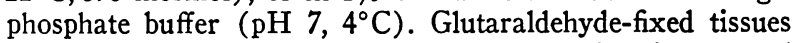
were postfixed $1 \mathrm{~h}$ in $1 \%$ osmium tetroxide in veronal buffer $(\mathrm{pH} 7.0)$ and stained en bloc for $1 \frac{1}{2} \mathrm{~h}$ in $2 \%$ uranyl acetate in veronal buffer $(\mathrm{pH} 5.5)$. All tissues were dehydrated in graded alcohols and embedded in Epon-Araldite plastic. After the presence of parathyroid tissue was confirmed by light microscopy, thin (ca. $400 \AA$ ) sections were prepared for electron microscopy and stained with uranyl acetate and Reynold's lead citrate.

Stereological analysis of tissue components. For microtubule analysis, five chief cells with recognizable Golgi areas were randomly selected from one glutaraldehyde-fixed parathyroid gland of each animal within a treatment category and photographed at a magnification of 16,000 . To avoid bias, cell selection was made without knowledge of the experimental group being evaluated, and was carried out at a magnification at which microtubules could not be identified by the microscopist. Microtubules in both transverse and longitudinal profile were subsequently identified on the resulting photographic prints. Longitudinal profiles of microtubules appeared as elongated, gently curving, or straight unbranched cylindrical elements, approximately $250 \AA$ in diameter. The minimal length of such a structure recognizable as a portion of a microtubule was about two times the microtubule diameter, or approximately $500 \AA$. Transverse sections of microtubules appeared as well-defined hollow circles of approximately $250 \AA$, which were generally set apart from other cytoplasmic structures by a distance of at least $250 \AA$. Structures which did not clearly adhere to the above descriptions were not included in the assessment of microtubule volume. Estimation of the volume density of microtubules within the cell cytoplasm was determined by the point-counting stereological method of Weibel (23), in which a grid with a $2-\mathrm{mm}$ lattice was used to estimate microtubule volume and a grid with a $2-\mathrm{cm}$ lattice was used to estimate cytoplasmic volume. The volume density of microtubules is given by the formula $(P)$ microtubules $/[(P)$ cytoplasm $\times 100]$ in which $(P)$ represents the number of lattice points enclosed by a given structure.

The stereological method as it applies to estimations of microtubule volume density is highly reproducible; i.e., the coefficient of variation when individual prints are reestimated five times is less than $5 \%$. However, certain technical problems which relate to the small diameter of microtubules, makes it difficult to obtain precise values for absolute microtubule volume density. On the one hand, microtubule volume density may be somewhat underestimated since not all segments of microtubules can be recognized on the photographic prints. On the other hand, microtubule volume density may also be somewhat overestimated since the longitudinal lengths of microtubules are assumed to occupy the full thickness of the sectioned portion of the cell in which they are found, and this is clearly not the case since the diameter of individual microtubules is always less than the diameter of the sections. The extent to which these errors distort the actual values for microtubule vol-
TABLE 1

Plasma Calcium (mean $\pm S E)$

\begin{tabular}{|c|c|c|c|c|}
\hline \multirow[b]{2}{*}{ Treatment } & \multirow[b]{2}{*}{ Dose } & \multirow{2}{*}{$\begin{array}{l}\text { Number } \\
\text { of rats }\end{array}$} & \multicolumn{2}{|c|}{ Calcium } \\
\hline & & & $90 \mathrm{~min}$ & $180 \mathrm{~min}$ \\
\hline & $\begin{array}{c}m g / k g \\
b o d y ~ w t\end{array}$ & & \multicolumn{2}{|c|}{$\mathrm{mg} / 100 \mathrm{ml}$} \\
\hline Saline & - & 10 & $10.17 \pm 0.09$ & $10.18 \pm 0.15$ \\
\hline \multirow[t]{4}{*}{ Colchicine } & 0.25 & 10 & $10.14 \pm 0.15$ & $10.03 \pm 0.11$ \\
\hline & 1.00 & 10 & $9.83 \pm 0.13$ & $9.27 \pm 0.11^{*}$ \\
\hline & 2.50 & 10 & $9.45 \pm 0.20^{*}$ & $8.44 \pm 0.16^{*}$ \\
\hline & 5.00 & 10 & - & $8.56 \pm 0.14^{*}$ \\
\hline Phosphorus & 150.00 & 10 & $9.20 \pm 0.15^{*}$ & $8.65 \pm 0.15^{*}$ \\
\hline Phosphorus plus & 150.00 & & & \\
\hline Colchicine & $\begin{array}{l}+ \\
2.50\end{array}$ & 10 & - & $7.02 \pm 0.18^{*}$ \\
\hline
\end{tabular}

$* P<0.01$ as compared to saline control at same time period.

ume density is not known. However, since the errors in the method will apply equally to tissues from both control and experimental groups of animals, it should be possible to discern relative differences in cytoplasmic microtubule volume density between the different groups of animals studied.

The volume density of secretion granules was obtained from the Golgi areas of five randomly selected chief cells of one osmium-fixed parathyroid gland from each rat within a treatment category. Secretion granules are defined as membrane-bound inclusion granules ranging in size from 0.15 to $0.5 \mu \mathrm{m}$, which have a uniformly dense interior and which closely resemble secretory granules from other tissues. The volume density of these granules was obtained by the point-counting stereological method mentioned above, although in this instance a $1-\mathrm{cm}$ lattice was used to estimate both granule and cytoplasmic volume. The volume density of granules was given by the formula $(P)$ granules/ $(P)$ cytoplasm.

\section{RESULTS}

The effect of colchicine and phosphorus treatment on plasma calcium levels. Table I indicates that both colchicine and phosphorus produced statistically significant falls in calcium levels. In each instance, lower calcium levels were observed at $180 \mathrm{~min}$ than at $90 \mathrm{~min}$. The effect of colchicine was dose related; no changes occurred in calcium levels after the administration of $0.25 \mathrm{mg} / \mathrm{kg}$ colchicine, but a significant depression of plasma calcium was seen after treatment with either $1.0,2.5$, or $5.0 \mathrm{mg} / \mathrm{kg}$ of colchicine. In addition, when phosphorus and $2.5 \mathrm{mg} / \mathrm{kg}$ colchicine were administered

bodies such as granules. Mitochondria, polysomes, and elements of the endoplasmic reticulum appear randomly distributed throughout the cells. However, granules (arrows), and other inclusion bodies when present, tend to accumulate in the Golgi (Go) region. $\times 16,800$. $1 \mathrm{~A}$ : A typical chief cell from a saline-treated rat showing only a single, small granule (arrow). Insert to 1A: an enlarged view of an inclusion body assumed to be a secretory granule. Structures such as these were identified at a magnification of $\times 44,000$ as shown, and subsequently quantitated by stereological techniques. 1B: Typical chief cells from a colchicinetreated rat $(2.5 \mathrm{mg}$ colchicine $/ \mathrm{kg}$ body $\mathrm{wt}$ ) showing several granules (arrows) of different sizes. 


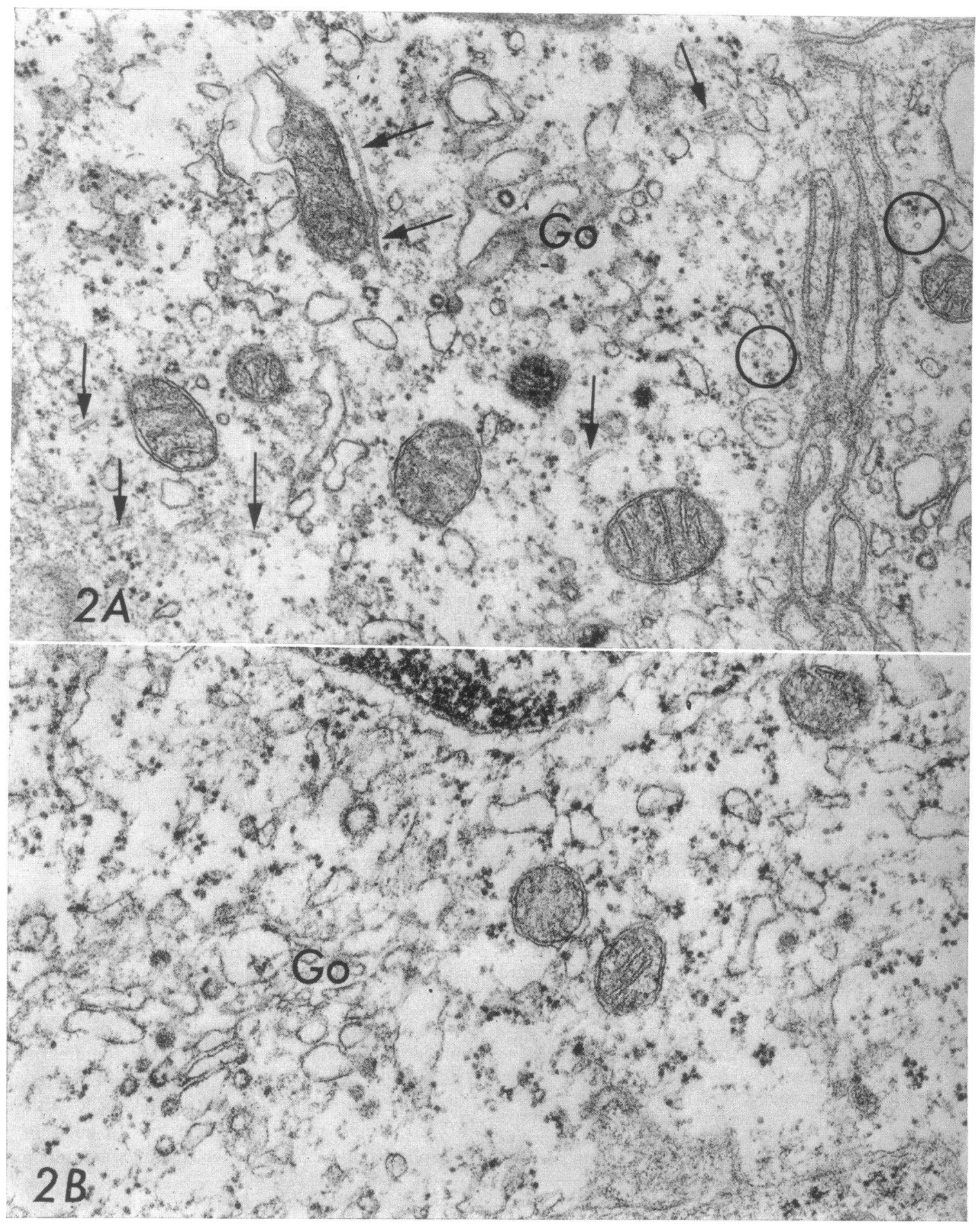

Figure 2 Golgi regions (Go) of chief cells of parathyroid glands typical of those used in quantitating the microtubule content of cells. Longitudinal segments of microtubules are shown by arrows; cross-sections of microtubules are circled. Glutaraldehyde fixation $\times 44,000$. 2A: Portion of cell from saline-treated rat. Arrows and circles indicate numerous segments of microtubules randomly oriented in normal cells. 2B: Portion of cell from colchicine-treated $(2.5 \mathrm{mg} / \mathrm{kg})$ rat. No microtubules are present. 
TABLE II

Mean $( \pm S E)$ Volume Density $\left(\times 10^{4}\right)$ of Microtubules in Cytoplasm of Chief Cells of Rat Parathyroid Glands 3 h after Treatment

\begin{tabular}{|c|c|c|c|c|c|}
\hline \multirow[b]{2}{*}{ Saline } & \multicolumn{3}{|c|}{ Colchicine } & \multirow{2}{*}{$\begin{array}{r}\text { Phosphorus, } \\
150 \mathrm{mg} / \mathrm{kg}\end{array}$} & \multirow{2}{*}{$\begin{array}{l}\text { Phosphorus }+ \text { colchicine } \\
150 \mathrm{mg} / \mathrm{kg}+2.5 \mathrm{mg} / \mathrm{kg}\end{array}$} \\
\hline & $0.25 \mathrm{mg} / \mathrm{kg}$ & $1.0 \mathrm{mg} / \mathrm{kg}$ & $2.5 \mathrm{mg} / \mathrm{kg}$ & & \\
\hline 7.92 & 6.12 & 1.64 & 0.00 & 10.80 & 0.00 \\
\hline 7.00 & 8.08 & 2.22 & 0.00 & 14.02 & 0.00 \\
\hline 7.85 & 4.12 & 1.64 & 0.00 & 8.41 & 0.01 \\
\hline 5.88 & 6.40 & 4.41 & 0.00 & 11.23 & 0.00 \\
\hline 6.52 & & & & 12.48 & \\
\hline 7.72 & & & & 12.68 & \\
\hline $7.13 \pm 0.33$ & $6.15 \pm 0.8$ & $2.45 \pm 0.67^{*}$ & $0.00^{*}$ & $11.58 \pm 0.79^{*}$ & $0.00^{*}$ \\
\hline
\end{tabular}

The value of each individual animal represents the mean microtuble content of five cells.

${ }^{*} P<0.01$ as compared to saline-treated controls.

simultaneously to rats, the resulting hypocalcemia was more profound than that observed after the administration of either phosphorus or colchicine alone.

Ultrastructural observations. To demonstrate both microtubule and secretory granules to best advantage, it was necessary to separately process the parathyroid glands using glutaraldehyde as the primary fixative for microtubules and osmium tetroxide as the primary fixative for granules.

Fig. 1 shows a typical low magnification view of portions of several chief cells preserved with osmium tetroxide. Fig. 1A, taken from a saline-treated rat, indicates that mitochondria, polysomes, and elements of the endoplasmic reticulum appear randomly distributed throughout the cells. These cells have a few inclusion bodies; the majority of these appear to be lysosomes but an occasional homogenous granule can be seen (arrow). On higher magnification (see inset to 1A) such granules with homogenously dense interiors limited by unit membranes resemble secretory granules of other cell types and are identified as such, for comparative purposes in this report. After colchicine treatment (Fig. 1B), or colchicine and phosphate treatment (not shown), there appears to be an increase in secretory granules (arrows) in the Golgi region (Go) of the chief cells. To verify these impressions, photographs were taken of the Golgi region of randomly selected cells at higher magnification and the secretory granule content of chief cells of parathyroid glands of rats treated with colchicine and/or phosphorus was estimated by stereological techniques.

Fig. 2 shows representative Golgi areas (Go) of chief cells from glutaraldehyde-fixed glands. Inspection of such cells from saline (Fig. 2A) or phosphorustreated rats (figure not shown) indicates the presence of numerous segments of microtubules (arrows). The microtubules appear to be randomly oriented; that is, no particular spatial association of microtubules with secretory granules, Golgi complexes, nuclear or plasma membranes is seen. After colchicine treatment (Fig. 2B) or administration of colchicine and phosphorus (not shown) the microtubule content of chief cells appears to be dramatically reduced. To document and compare these effects, photographs were taken of randomly selected chief cell Golgi areas. The enlarged photographic prints of these cells were subsequently subjected to microtubule quantitation by stereological procedures.

Effect of colchicine and/or phosphorus on the microtubule content of chief cells. Changes in microtubule content (as assessed by stereological measurements) $3 \mathrm{~h}$ after treatment of rats with colchicine and phosphorus are seen in Table II.

TABLE III

Cytoplasmic Granule Content of Chief Cells of Rat Parathyroid Glands 3 h after Treatment

\begin{tabular}{lccc}
\hline \multicolumn{1}{c}{ Treatment } & Dose & $\begin{array}{c}\text { Number } \\
\text { of } \\
\text { animals }\end{array}$ & $\begin{array}{c}\text { Volume density } \\
\text { of granules } \times 10^{3} \\
\text { (mean } \pm \mathrm{SE} \text { ) }\end{array}$ \\
\hline & $\begin{array}{c}m g / k g \\
\text { body } w t\end{array}$ & & \\
Saline & - & 10 & $3.6+0.8$ \\
Colchicine & 1.0 & 5 & $7.8 \pm 2$ \\
& 2.5 & 10 & $10.0 \pm 1 \ddagger$ \\
Phosphorus & 5.0 & 5 & $10.6 \pm 1 \ddagger$ \\
Phosphorus plus & 150.0 & 6 & $3.4 \pm 0.5$ \\
Colchicine & 150.0 & & \\
& + & 6 & $15.8 \pm 3.5 \ddagger$ \\
& 2.5 & & \\
\hline
\end{tabular}

* Values represent mean granule content of five cells from each of indicated number of animals.

$\ddagger P<0.01$ as compared to saline-treated controls. 
The most striking finding was the absence of microtubules from cells of rats receiving $2.5 \mathrm{mg}$ of colchicine $/ \mathrm{kg}$ body wt (see Fig. 2). Microtubule content was also significantly decreased $(P<0.01)$ after the intermediate dose of colchicine $(1.0 \mathrm{mg} / \mathrm{kg})$, but was not significantly decreased from normal in cells of rats receiving $0.25 \mathrm{mg}$ of colchicine $/ \mathrm{kg}$ body wt. In contrast, phosphorus administration resulted in a significant increase $(P<0.01)$ in the microtubule content of chief cell cytoplasm, the mean value of cytoplasmic microtubule content being greater in each phosphorus-treated animals than in any control animal. When colchicine $(2.5 \mathrm{mg} / \mathrm{kg})$ and phosphorus are given simultaneously however, the increase in microtubule content observed after phosphorus treatment is completely inhibited.

Effect of colchicine and phosphorus on secretory granule content of chief cells. The impression that few secretory granules are present in cells from salinetreated rats is verified by stereological measurements and Table III indicates that the cytoplasmic volume density of such granules is very low; that is, only $0.36 \%$ of the cytoplasm of normal cells is occupied by granules. On the other hand, $3 \mathrm{~h}$ after treatment with colchicine there is a rise in the granule content of chief cells (see Fig. 1). The extent of the rise, however, depends on the dose of colchicine given (Table III). At a colchicine dose of $1 \mathrm{mg} / \mathrm{kg}$, the mean granule content of chief cells, although double that of cells from control animals, is nevertheless not significantly different from normal. At $2.5 \mathrm{mg}$ colchicine $/ \mathrm{kg}$ body wt, the mean granule content of chief cells is almost triple that of control cells and becomes statistically different from controls; however, a further increase in the dose of colchicine (to $5.0 \mathrm{mg} / \mathrm{kg}$ ) shows no further rise in granule content.

Although treatment with phosphorus alone does not alter the cytoplasmic volume density of these granules, concomitant treatment with phosphorus and colchicine $(2.5 \mathrm{mg} / \mathrm{kg})$ results in a significantly greater $(58 \%)$ increase in granules than was seen after colchicine $(2.5$ $\mathrm{mg} / \mathrm{kg}$ ) alone (Table III).

\section{DISCUSSION}

The results of this study provide direct, morphological evidence that colchicine administration leads to a decrease in the microtubule content of chief cells of the rat parathyroid gland. As such, these data suggest that antimitotic agents which interfere with parathyroid hormone secretion $(4,5,14)$ do so by preventing microtubule assembly. Further evidence that microtubules are involved in the secretion of parathyroid hormone can be derived from the effect of colchicine on the relationship between volume density of secretory granules and of microtubules. Thus, $3 \mathrm{~h}$ after the administration of colchicine $(2.5 \mathrm{mg} / \mathrm{kg}$ body $\mathrm{wt}$ ), at a time when no microtubules are seen in parathyroid gland chief cells, the volume density of secretory granules had increased approximately threefold. The simplest explanation for the observed accumulation of secretory granules would seem to be that colchicine interferes with microtubule assembly, and thereby prevents hormone release. This effect of colchicine on microtubule assembly is clearly dose related, and the administration of increasing amounts of colchicine lead to progressively greater reductions in microtubule content. The observation that one can increase the colchicine dose beyond the concentration necessary to remove all microtubules (5.0 $\mathrm{mg} / \mathrm{kg}$ ) and not further increase the granule content of the chief cells, lends support to the idea that the increase in granule content is related to the loss of microtubules and is not a consequence of a direct effect of colchicine on granule production.

It should be noted that increasing amounts of colchicine also leads to progressive reductions in plasma calcium levels, reaching a maximum reduction, in our studies, after the administration of $2.5 \mathrm{mg}$ colchicine $/ \mathrm{kg}$ body wt. However, the fall in plasma calcium may not be entirely related to inhibition of parathyroid hormone secretion, as evidence has been published which suggests that colchicine also directly inhibits bone resorption $(6,24)$.

Evidence that changes in microtubule volume density may also be involved in the physiological control of parathyroid hormone secretion can be seen in the results of the studies of phosphorus-induced hypocalcemia. Previous results have indicated that phosphorus administration results in increased parathyroid hormone secretion when hypocalcemia ensues (21). The current results indicated that this phenomenon is also associated with an increase of the cytoplasmic microtubule content of chief cells of parathyroid glands. These results raise the interesting possibility that microtubule integrity may not only be necessary for secretion to take place, as suggested by the colchicine results, but that an increase in assembled microtubules (that is, microtubule content) may accompany or be required for increased parathyroid hormone secretion. Obviously, further quantitative studies will be necessary to test the general nature of this provocative finding.

In view of the phosphorus-induced hypocalcemia, and presumptive increase in hormone production and secretion, it was surprising not to find an increase in secretory granules within the chief cells of phosphorus-treated rats. One explanation of this finding is that both production and release of secretory granules is accelerated under these conditions. Were this the case, one might see an increased accumulation of secretory product within the cells if colchicine, which presumably blocks secretion, was given simultaneously with phosphorus. When this was done, a greater degree of hypocalcemia developed, indicating the additive effects of phosphorus and colchicine on serum calcium levels. 
Microtubules were absent from the parathyroid gland chief cells of animals receiving phosphorus plus colchicine, demonstrating that colchicine can even prevent microtubule assembly under conditions which would otherwise lead to an increase in microtubule content. However, the secretory granule content of the chief cells was significantly greater than that seen after colchicine or phosphorus treatment alone. This marked accumulation of secretory granules appears to reflect an increased rate of parathyroid hormone secretion due to the persistent hypocalcemia, which can only be documented when the release of the secretory granules is prevented by colchicine.

In conclusion, these results indicate that quantitative and reproducible estimates can be made of the cyptoplasmic content of microtubules and secretory granules in chief cells of rat parathyroid glands. Using this ultrastructural approach, we have obtained evidence which suggests that changes in the microtubule content of chief cells of parathyroid glands appear to parallel changes in parathyroid hormone secretion. Although these results are compatible with the thesis that microtubules participate in the control of parathyroid hormone secretion, confirmation of the causal relationship of these events awaits further experimentation. It is anticipated that this stereological approach will provide useful information in future studies of parathyroid hormone secretion.

\section{ACKNOWLEDGMENTS}

The authors wish to thank L. Hanahan, M. A. Johnson, and M. E. Menn for their excellent technical assistance and F. Conrad and Wm. Walker for their helpful suggestions in analyzing the morphometric data.

This work was supported by the Veterans Administration.

\section{REFERENCES}

1. Lacy, P. E., S. Howell, D. Young, and C. J. Fink. 1968. New hypothesis of insulin release. Science (Wash. D. C.). 219: 1177-1179.

2. Lacy, P. E., M. M. Walker, and C. J. Fink. 1972. Perfusion of isolated rat islets in vitro. Participation of the microtubular system in the biphasic release of insulin. Diabetes. 21 : 987-998.

3. Williams, J. A., and J. Wolff. 1972. Colchicine-binding protein and the secretion of thyroid hormone. J. Cell Biol. 54 : 157-165.

4. Chertow, B. S., G. A. Williams, K. L. Stewart, G. K. Hargis, R. L. Flayter, and R. M. Norris. 1973. The interactions between Vitamin A, vinblastine, and cytocholasin B in PTH secretion. Clin. Res. 21: 820. (Abstr.)

5. Kemper, B., J. F. Habener, A. Rich, and J. T. Potts, Jr. 1975. Microtubules and the intracellular conversion of proparathyroid hormone to parathyroid hormone. Endocrinology. 96: 903-912.

6. Raisz, L. G., M. E. Holtrop, and H. A. Simmons. 1973. Inhibition of bone resorption by colchicine in organ culture. Endocrinology. 92: 556-562.

7. Stein, O., and Y. Stein. 1973. Colchicine-induced inhibition of very low density lipoprotein release by rat liver in vivo. Biochim. Biophys. Acta. 306: 142-147.
8. Taylor, A., M. Mamelak, E. Reaven, and R. Maffly. 1973. Vasopressin: possible role of microtubules and microfilaments in its action. Science (Wash. D. C.). $181: 347-350$.

9. Chiraseveenuprapund, P., and I. N. Rosenberg. 1974. Effects of colchicine on the formation of thyroid hormone. Endocrinology. 94: 1086-1093.

10. Dousa, T. P., and L. D. Barnes. 1974. Effects of colchicine and vinblastine on the cellular action of vasopressin in mammalian kidney. A possible role of microtubules. J. Clin. Invest. $54:$ 252-262.

11. Devis, G., E. Van Obberghen, G. Somers, F. MalaisseLagae, L. Orci, and W. J. Malaisse. 1974. Dynamics of insulin release and microtubular-microfilamentous system. II. Effect of vincristin. Diabetologia. 10: 53-59.

12. Ekholm, R., L. E. Ericson, J-O. Josefson, and A. Melander. 1974. In vivo action of vinblastine on thyroid ultrastructure and hormone secretion. Endocrinology. 94 : 641-649.

13. Holtrop, M. E., L. G. Raisz, and H. A. Simmons. 1974. The effects of parathyroid hormone, colchicine, and calcitonin on the ultrastructure and the activity of osteoclasts in organ culture. J. Cell Biol. 60: 346-355.

14. Kemper, B., J. F. Habener, A. Rich, and J. T. Potts, Jr. 1974. Parathyroid secretion: discovery of a major calcium-dependent protein. Science (Wash. D. C.). 184: 167-169.

15. LeMarchand, Y. L., C. Patzelt, F. Assimacopoulos-Jeannet, E. Loten, and B. Jeanrenaud. 1974. Evidence for a role of the microtubular system in the secretion of newly synthesized albumin and other proteins by the liver. J. Clin. Invest. 53: 1512-1517.

16. Stein, O., L. Sanger, and Y. Stein. 1974. Colchicineinduced inhibition of lipoprotein and protein secretion into the serum and lack of interference with secretion of biliary phospholipids and cholesterol by rat liver in vivo. J. Cell Biol. 62: 90-103.

17. Taylor, A., L. Wilson, R. Maffly, and E. Reaven. 1975. Evidence for involvement of microtubules in the action of vasopressin. Ann. N. Y. Acad. Sci. 253: 723-737.

18. Wilson, L., and M. Friedkin. 1966. The biochemical events of mitosis. I. Synthesis and properties of colchicine labeled with Tritium in its acetyl moiety. Biochemistry. 5 : 2463-2468.

19. Borisy, G. G., and E. W. Taylor. 1967. The mechanism of action of colchicine. Binding of colchicine- ${ }^{3} \mathrm{H}$ to cellular protein. J. Cell Biol. 34 : 525-533.

20. Wilson, L., and I. Meza. 1973. The mechanism of action of colchicine. Colchicine binding properties of sea urchin sperm tail outer doublet tubulin. J. Cell Biol. 58: 709719.

21. Potts, J. T., Jr., R. M. Buckle, L. M. Sherwood, C. I. Ramberg, Jr., C. P. Mayer, D. S. Kronfeld, L. J. Deftos, A. D. Care, and G. D. Aurbach. 1968. Control of secretion of parathyroid hormone. In Parathyroid Hormone and Thyrocalcitonin. R. V. Talmage and L. F. Belangers, editors. Excerpta Medica, Amsterdam. 407417.

22. Gitelman, H. J. 1967. An improved automated procedure for the determination of calcium in biological speciments. Anal. Biochem. 18: 521-531.

23. Weibel, E. R. 1969. Stereological principles for morphometry in electron microscopic cytology. Int. Rev. Cytol. 26: 235-302.

24. Heath, D. A., J. S. Palmer, and G. D. Aurbach. 1972. The hypocalcemic action of colchicine. Endocrinology. 90 : 1589-1593. 